\title{
The effects of short-term genistein intervention on prostate biomarker expression in patients with localised prostate cancer before radical prostatectomy
}

\author{
Bato Lazarevic $^{1 *}$, Clara Hammarström², Jin Yang ${ }^{3}$, Hakon Ramberg $^{1}$, Lien M. Diep ${ }^{4}$, Steinar J. Karlsen ${ }^{1,5}$, \\ Omer Kucuk $^{6}$, Fahri Saatcioglu ${ }^{3}$, Kristin A. Taskèn ${ }^{1,5}$ and Aud Svindland ${ }^{5,7}$ \\ ${ }^{1}$ Department of Urology, Institute of Cancer Research, Oslo University Hospital, The Norwegian Radiumbospital, \\ Montebello, 0310 Oslo, Norway \\ ${ }^{2}$ Department of Pathology, Oslo University Hospital, Rikshospitalet, Oslo, Norway \\ ${ }^{3}$ Department of Molecular Biosciences, University of Oslo, Oslo, Norway \\ ${ }^{4}$ Unit for Biostatistics and Epidemiology, Oslo University Hospital, Oslo, Norway \\ ${ }^{5}$ Department of Clinical Medicine, University of Oslo, Olso, Norway \\ ${ }^{6}$ Department of Medical Oncology, Emory University, Atlanta, GA, USA \\ ${ }^{7}$ Department of Pathology, Oslo University Hospital, Aker, Norway
}

(Submitted 2 December 2011 - Final revision received 16 January 2012 - Accepted 16 January 2012 - First published online 8 March 2012)

\begin{abstract}
Nutritionally relevant levels of genistein, the predominant isoflavone in soyabean associated with lower risk of prostate cancer (PCa), may modulate the expression of prostate tissue biomarkers associated with cancer prediction and progression. A phase 2 placebocontrolled, randomised, double-blind clinical trial was conducted in forty-seven Norwegian patients before prostatectomy. Intervention was $30 \mathrm{mg}$ genistein or placebo capsules daily for 3-6 weeks. Luminal cells from malignant and benign glands were isolated with laser capture microdissection and the mRNA levels of androgen-related biomarkers (androgen receptor, NK3 homeobox 1, kallikrein-related peptide 4 (KLK4)) and cell cycle-related genes $\left(p 21^{\text {Waf1/Cip1 }}, p 27^{\text {Kip1 }}\right.$, p53) were analysed with real-time semiquantitative PCR. Immunohistochemistry of androgen-, cell cycle-, proliferative- (Ki67 nuclear antigen), apoptotic- (B-cell CLL/lymphoma 2 (BCL-2) and BCL-2-associated X protein) and neuroendocrine differentiation-related biomarkers (neuron-specific enolase and cytoplasmic chromogranin A) was performed using tissue microarrays containing normal, Gleason grade 3 and grade 4 prostate tissues. There were no significant effects by genistein intervention on proliferation-, cell cycle-, apoptosis- or neuroendocrine biomarkers. Genistein intervention, however, significantly reduced the mRNA level of KLK4 in tumour cells $(P=0.033)$ and there was a nonsignificant reduction in androgen and cell cycle-related biomarkers, except for $\mathrm{p} 27^{\mathrm{Kip} 1}$, whose expression in the nuclear compartment was increased. Genistein intervention modulated the expression of several biomarkers which may be related to PCa prediction and progression. The present study supports genistein as a chemopreventive agent in PCa. Further investigation is warranted in larger and longer-duration studies.
\end{abstract}

Key words: Biomarkers: Genistein: Immunohistochemistry: PCR: Prostate cancer

Although not an ideal biomarker, serum prostate specific antigen is the only predictive and prognostic prostate cancer (PCa) biomarker widely used in clinical practice. Several proteins have been proposed as candidate biomarkers exhibiting all or some of these predictive or prognostic properties ${ }^{(1-3)}$. Among these are androgen-, cell cycle-, proliferation-, apoptosis- and neuroendocrine differentiation-related biomarkers.
The soya isoflavone, genistein, is a promising chemopreventive agent in PCa based on molecular, epidemiological and clinical studies ${ }^{(4,5)}$. We have previously reported the clinical endpoints of a phase 2 clinical randomised trial with short-term genistein intervention in patients with localised PCa. Genistein reduced the level of serum prostate specific antigen without any effects on hormones ${ }^{(6)}$. The purpose of

Abbreviations: AR, androgen receptor; BAX, B-cell CLL/lymphoma 2-associated X protein; BCL-2, B-cell CLL/lymphoma 2; CgA, cytoplasmic chromogranin A; G3, Gleason grade 3; G4, Gleason grade 4; KLK4, kallikrein-related peptide 4; NKX3·1, NK3 homeobox 1; NSE, neuron-specific enolase; p21 Waf1/Cip1 , cyclindependent kinase inhibitor $1 \mathrm{~A} ; \mathrm{p} 27^{\mathrm{Kip} 1}$, cyclin-dependent kinase inhibitor $1 \mathrm{~B}$; $\mathrm{p} 53$, tumour protein $\mathrm{p} 53$; PCa, prostate cancer.

*Corresponding author: B. Lazarevic, fax + 47 22935944, email bato.lazarevic@medisin.uio.no 
Table 1. Primers for PCR

\begin{tabular}{lll}
\hline Gene & Forward primer & Reverse primer \\
\hline$A R$ & TGGAAGCTGCAAGGTCTTCT & AAGCCTCTCCTTCCTCCTGT \\
$K L K 4$ & ATGGAAAACGAATTGTTCTGCTC & CAGCACGGTAGGCATTCTG \\
NKX3.1 & GGCCTGGGAGTCTCTTGACTCCACTAC & ATGTGGAGCCCAAACCACAGAAAAATG \\
$p 21$ & AGGGGACAGCAGAGGAAGA & CTTCCTGTGGGCGGATTAG \\
$p 27$ & TCAGAAGACGTCAAACGTAAACA & CCAACGCTTTTAGAGGCAGA \\
$p 53$ & CCCCAGCCAAAGAAGAAAC & TTTTTATGGCGGGAGGTAGA \\
ALAS1 & CTGCAAAGATCTGACCCCTC & CCTCATCCACGAAGGTGATT \\
\hline
\end{tabular}

$A R$, androgen receptor; $K L K 4$, kallikrein-related peptide 4; NKX3.1, NK3 homeobox $1 ; p 21$, cyclin-dependent kinase inhibitor $1 \mathrm{~A} ; p 27$, cyclin-dependent kinase inhibitor 1B; $p 53$, tumour protein p53; $A L A S I$, aminolevulinate synthase gene.

the present study was to investigate the modulation of potential candidate PCa tissue biomarkers by genistein at a dose that can be obtained from a diet rich in soya-based food.

\section{Experimental methods}

\section{Patients and study design}

A total of forty-seven patients with localised PCa scheduled to be treated by radical prostatectomy were randomised during April 2007-August 2008. Next, a total of forty-one prostates were analysed and forty were considered as evaluable according to the study protocol. However, one specimen only contained enough tumour material for pathological analysis and could therefore not be analysed for biomarkers. The study was a single-centre, placebo-controlled, randomised and double-blind phase 2 clinical trial with two treatment arms ${ }^{(6)}$. One arm was given $30 \mathrm{mg}$ synthetic genistein (geniVida ${ }^{\circledR(7)}$ ) daily and one arm received placebo. The intervention period was 3-6 weeks (average 33 d) before radical prostatectomy. This study was conducted according to the guidelines laid down in the Declaration of Helsinki and all procedures involving human subjects/patients were approved by the Norwegian Medicines Agency, the Regional Ethics Committee, the Privacy Ombudsman and the Prostate Biobank at the Oslo University Hospital, Aker. Written informed consent was obtained from all subjects/patients. The study has been registered in the ClinicalTrials.gov registry (study identifier: NCT00546039).

\section{Tissue processing, laser capture microdissection and RNA isolation}

After surgery, the prostates were immediately transferred to the pathology department and macro-dissected by a pathologist. Fresh tissue cubes, approximately $0.5 \mathrm{~cm}^{3}$, were cut from tumour and normal tissue and frozen at $-80^{\circ} \mathrm{C}$. Frozen $10 \mu \mathrm{m}$ sections were stained with haematoxylin and eosin. At least 10000 cells from histologically benign and cancer glands from each patient were selected and captured using laser capture microdissection (Leica LMD 6000; Leica Microsystems) and frozen at $-80^{\circ} \mathrm{C}^{(8)}$.

Total RNA was isolated using the Arcturus PicoPure RNA Isolation Kit (Molecular Devices) according to the manufacturer's protocol. The concentration of RNA was determined by measurements in the NanoDrop ND-1000 spectrophotometer (NanoDrop Technologies). Reverse transcription of
50 ng total RNA was performed with the iScript cDNA Synthesis Kit (Bio-Rad) according to the manufacturer's protocol. Although fresh prostate tissue was acquired from most patients, tumour was found in only ten study subjects from the genistein arm and twelve from the placebo arm.

\section{Semi-quantitative real-time RT PCR}

Primers were designed with Primer3 provided by the Whitehead Institute for Biomedical Research (http://fokker.wi.mit. edu/cgibin/primer3/primer3_www.cgi). Sequences are listed in Table 1. Relative quantification of gene expression by semi-quantitative real-time RT-PCR was performed by analysing the expression of human housekeeping delta-aminolevulinate synthase gene. Real-time PCR was performed on the Bio-Rad Opticon DNA Engine. All amplifications were run as triplicates with standard curves. Here, 1 ng of template was used in each reaction following the manufacturer's protocol (Bio-Rad SYBR Green Master Mix). The same set-up was used for all primers (sixty-six cycles of $55^{\circ} \mathrm{C}$ annealing, $72^{\circ} \mathrm{C}$ extension and $90^{\circ} \mathrm{C}$ denaturing).

\section{Tissue processing and immunohistochemical analysis}

The prostates were fixed in $10 \%$ buffered formalin, macrodissected and paraffin-embedded. Tissue microarrays were

Table 2. Antibodies for immunohistochemistry

\begin{tabular}{lllll}
\hline Antigen & Clone & Supplier & Dilution & Treatment \\
\hline AR & MS-443 & Thermo Scientific & Prediluted & Benchmark XT \\
KLK4 & Rabbit & F.S lab & $3 \mu \mathrm{g} / \mathrm{ml}$ & Autoclave \\
NKX3.1 & Rabbit & F.S lab & $1 \mu \mathrm{gl}$ & Autoclave \\
p21 & EA-10 & Calbiochem & $0.25 \mu \mathrm{g} / \mathrm{ml}$ & PT-module \\
p27 & SC-528 & Santa Cruz & $1 \mu \mathrm{gl} /$ & PT-Module† \\
p53 & Bp53-11 & Roche & Prediluted & Benchmark XT \\
Ki67 & $30-9$ & Roche & Prediluted & Benchmark XT \\
BAX & $2 D 2$ & Thermo Scientific & $12 \cdot 5 \mu \mathrm{g} / \mathrm{ml}$ & PT-moduleł \\
BCL-2 & 124 & Roche & Prediluted & Benchmark XT \\
NSE & E27 & Roche & Prediluted & Benchmark XT \\
CgA & LK2H10 & Roche & Prediluted & Benchmark XT
\end{tabular}

AR, androgen receptor; KLK4, kallikrein-related peptide 4; NKX3.1, NK3 homeobox 1; p21, cyclin-dependent kinase inhibitor 1A; p27, cyclin-dependent kinase inhibitor 1B; p53, tumour protein p53; BAX, B-cell CLL/lymphoma 2-associated X protein; BCL-2, B-cell CLL/lymphoma 2; NSE, neuron-specific enolase; CgA, cytoplasmic chromogranin A.

* Citrate buffer $\mathrm{pH} 6$

†Tris buffer $\mathrm{pH} 9$.

‡DTA buffer $\mathrm{pH} 8$. 

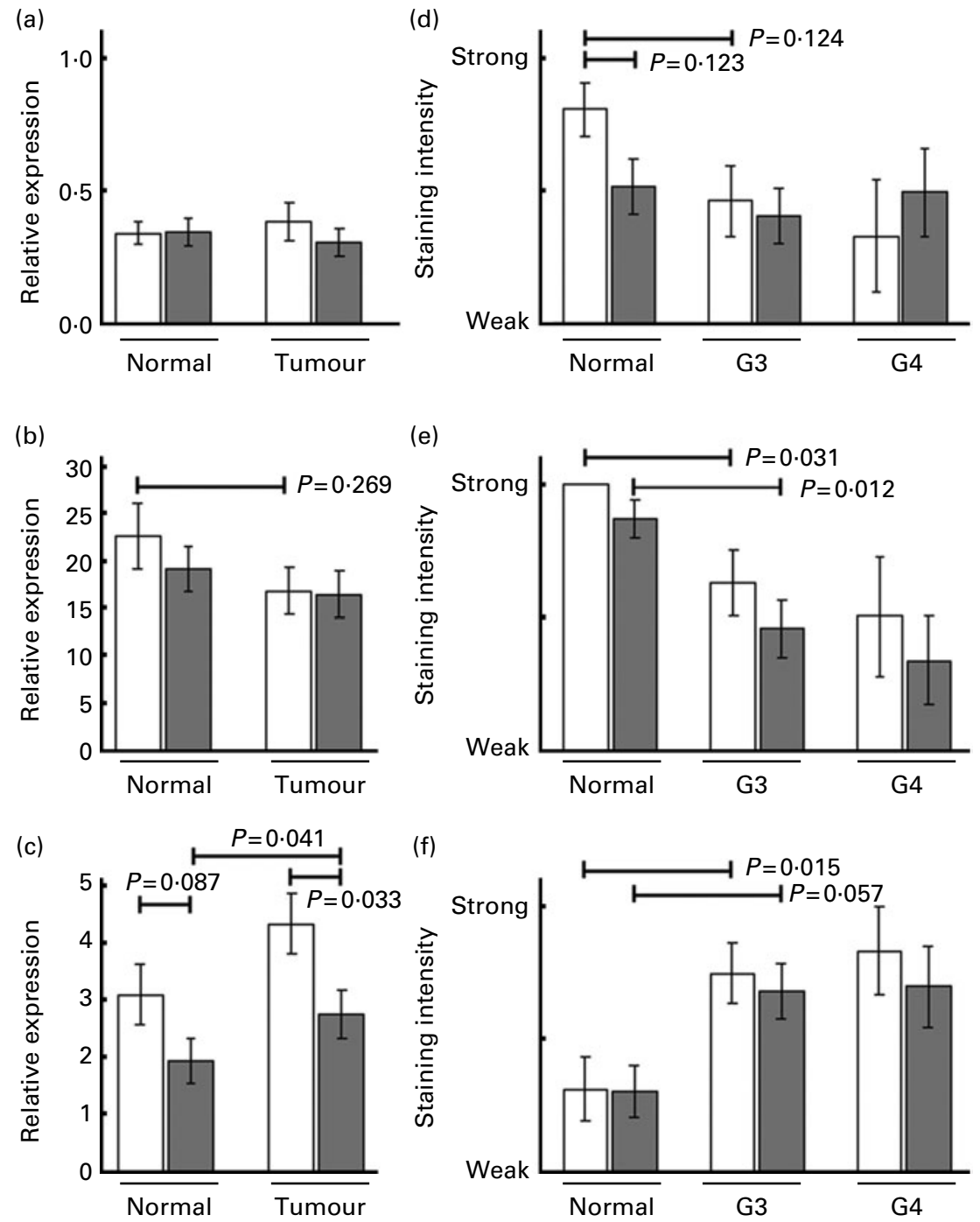

Fig. 1. Expression of androgen-related biomarkers. Real-time RT-PCR of the mRNA expression of (a) androgen receptor (AR), (b) NK3 homeobox 1 (NKX3.1) and (c) kallikrein-related peptide 4 (KLK4) in laser micro-dissected cells from normal and tumour areas of prostatectomy specimens from patients treated with either placebo $(\square)$ or genistein $(\square)$. The data were normalised to aminolevulinate synthase gene and are shown as means, with their standard errors. The protein expression levels of (d) AR, (e) NKX3.1 and (f) KLK4 were determined by immunohistochemical staining of tissue microarrays containing normal and Gleason grade 3 (G3) and/or Gleason grade 4 (G4) spots of prostatectomy specimens. The figures show the mean staining intensity, with their standard errors.

assembled using the TMABooster (Alphelys) sampler. Normal, Gleason grade 3 (G3) and Gleason grade 4 (G4), if available, prostate tumours were marked on haematoxylin/ eosin-stained sections. From each patient, three $0.6 \mathrm{~mm}$ biopsy cores were taken from normal prostatic tissue and each available Gleason grade tumour. The sampling size of three cores has previously been shown to be representative of $\mathrm{PCa}^{(9)}$. Next, $10 \mu \mathrm{m}$ tissue microarray sections on glass slides (SuperFrost ${ }^{\circledR}$ ) were treated according to the procedures listed in Table 2. 'Benchmark XT' used automated immunohistochemical staining (Benchmark XT; Ventana Medical Systems). The slides were treated in a dry cabinet for $60 \mathrm{~min}$ at $60^{\circ} \mathrm{C}$, cooled and washed with a detergent before conditioning with cell conditioning 1 (CC1) buffer (Ventana Medical Systems). Detection of the bound primary antibody was visualised with the iView $^{\mathrm{TM}}$ DAB Detection kit
(Ventana Medical Systems). The cells were counterstained with haematoxylin and Bluing reagent (Ventana Medical Systems) for $4 \mathrm{~min}$. 'Autoclave' used citrate buffer $\mathrm{pH} 6.4$ at $120^{\circ} \mathrm{C}$ for $40 \mathrm{~min}$ for antigen retrieval. Immunohistochemistry was performed according to the manufacturer's protocol (BioGenex Detection kit). The slides were visualised by diaminobenzidine staining followed by haematoxylin staining. 'PT-module' used different buffers according to Table 2. The slides were treated in $98^{\circ} \mathrm{C}$ for $25 \mathrm{~min}$ in the PT-Module (Lab Vision Corporation) for antigen retrieval. Immunohistochemistry and visualisation were performed according to the manufacturer's protocol (UltraVision ONE Detection System; Thermo Fisher Scientific). The cells were counterstained with haematoxylin. The stained tissues were then independently analysed by two consultant pathologists (A. S. and C. H.), who later made a consensus evaluation 
on each sample. Samples not containing the designated Gleason grade were not analysed and treated as missing.

The staining intensities of nuclear androgen receptor (AR), cytoplasmic and nuclear NK3 homeobox 1 (NKX3.1), cytoplasmic kallikrein-related peptide 4 (KLK4), cytoplasmic and nuclear cyclin-dependent kinase inhibitor $1 \mathrm{~B}\left(\mathrm{p} 27^{\mathrm{Kip} 1}\right)$ and cytoplasmic B-cell CLL/lymphoma 2-associated X protein (BAX) were scored as either weak/moderate (0) or strong (1), whereas the staining intensities of cytoplasmic B-cell CLL/ lymphoma 2 (BCL-2), cytoplasmic neuron-specific enolase (NSE: also called ENO2) and cytoplasmic chromogranin A (CgA) were scored as negative (0) or positive cytoplasmic staining (1).

Sample sizes for the placebo arm were: sixteen containing normal glandular tissue, sixteen G3 and six G4 tumours; and for the genistein arm: twenty-three normal glandular tissue, twenty-two G3 and ten G4. In the placebo arm, one G3 disappeared due to technical reasons for $\mathrm{AR}$ and $\mathrm{p} 27^{\mathrm{Kip} 1}$. In the genistein arm, one G4 disappeared for NKX3.1 and cyclin-dependent kinase inhibitor $1 \mathrm{~A}\left(\mathrm{p} 21^{\text {Waf1/Cip1 }}\right)$.

\section{Statistical analysis}

Values are expressed as means with their standard errors for continuous and ordinal data. Differences between two related and independent samples were tested by Fisher-Pitman permutation tests for paired and two-sample interval-scaled data. The $P$-values were based on 2000 simulations and considered significant at $P<0.050$. The analyses were carried out in STATA/IC 11.1 for Windows (32-bit) and Sigmaplot 11.0 for Windows was used to create the figures.

\section{Results}

\section{Androgen-related biomarkers}

Genistein intervention significantly reduced KLK4 mRNA expression in tumour cells $(P=0.033)$. The down-regulation of AR protein expression and KLK4 mRNA level in normal cells were not statistically significant $(P=0.123$ and $P=0.087$; Fig. 1(c) and (d)). There was a general non-significant tendency by genistein intervention to reduce the expression of androgen-related biomarkers (Fig. 1).

The AR and NKX3.1 nuclear protein expression in both study arms were reduced in higher Gleason grades, whereas both the mRNA and protein expression were increased for KLK4. AR mRNA expression was unchanged. Fig. 2(a) depicts a patient treated with placebo showing strong nuclear AR staining intensity in normal cells and weak intensity in the case of tumour. The cytoplasmic expression of NKX3.1 was equivalently increased (data not shown). Fig. 2(b) shows a patient from the genistein group with strong nuclear/weak cytoplasmic NKX3.1 staining intensity in normal cells and weak nuclear/strong cytoplasmic staining intensity in tumour. Fig. 2(c) depicts a patient treated with genistein showing weak cytoplasmic KLK4 staining intensity in normal cells and strong intensity in tumour.

\section{Cell cycle-related biomarkers}

Genistein intervention had no significant effects on $\mathrm{p} 21^{\text {Waf1/Cip1 }}$, $\mathrm{p} 27^{\mathrm{Kip} 1}$ or tumour protein $\mathrm{p} 53$ (p53) mRNA and protein expression (Fig. 3). There was a non-significant reduction in

(a)

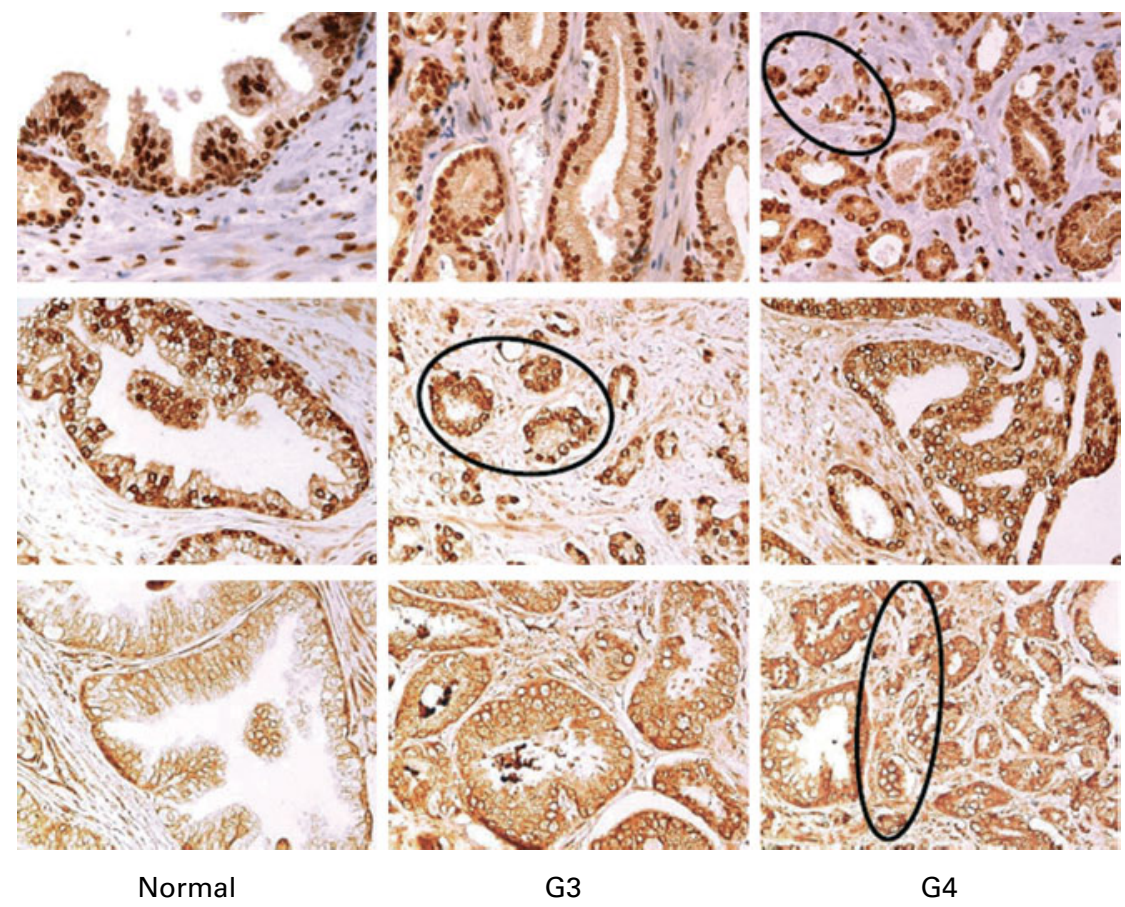

Fig. 2. Immunohistochemical staining of androgen-related biomarkers. Each row shows tissue microarray spots from a single patient containing normal, Gleason grade 3 (G3) and Gleason grade 4 (G4) prostate tissues. Encircled areas contain designated Gleason grade. Magnification $\times 400$. (a) Androgen receptor, (b) NK3 homeobox 1 and (c) kallikrein-related peptide 4. 

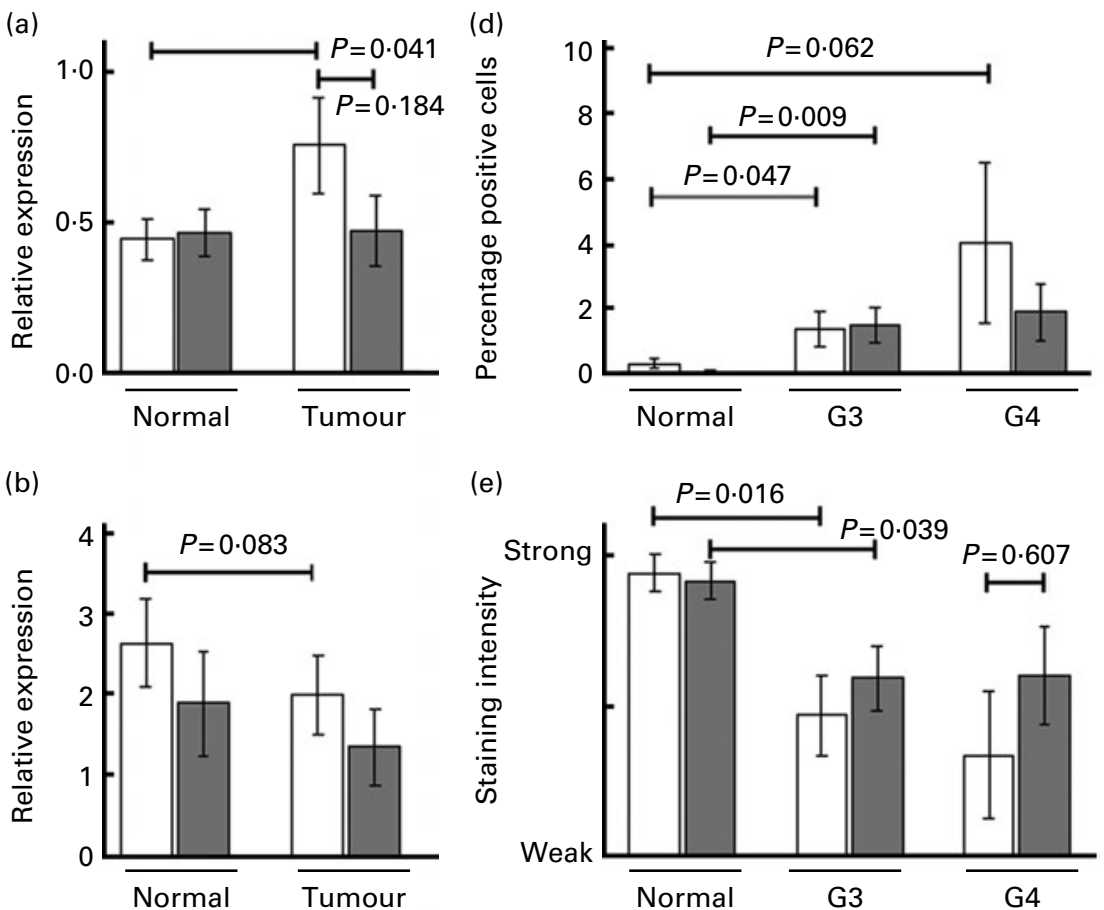

(c)

(f)
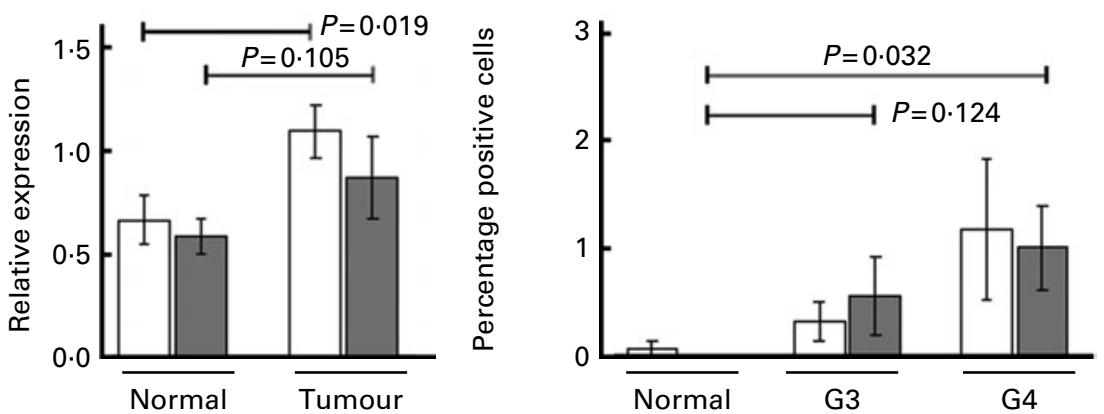

Fig. 3. Expression of cell cycle-related biomarkers. Real-time RT-PCR of the mRNA expression of (a) cyclin-dependent kinase inhibitor $1 \mathrm{~A}$ ( $\mathrm{p} 21^{\text {Waf1/Cip1) }}$, (b) cyclin-dependent kinase inhibitor 1B (p27 ${ }^{\text {Kip1 }}$ ) and (c) tumour protein p53 (p53) in laser micro-dissected cells from normal and tumour areas of prostatectomy specimens from patients treated with either placebo $(\square)$ or genistein $(\square)$. The data were normalised to aminolevulinate synthase gene and are shown as means, with their standard errors. The protein expression level of (d) p21 $1^{\text {Waf1/Cip1 }}$, (e) p27 $7^{\text {Kip1 }}$ and (f) p53 was determined by immunohistochemical staining of tissue microarrays containing normal and Gleason grade 3 (G3) and/or Gleason grade 4 (G4) spots of prostatectomy specimens. The figures show the mean staining intensity or percentage positive cells, with their standard errors.

the expression of $\mathrm{p} 21^{\text {Waf1/Cip } 1}$ mRNA expression in tumour $(P=0 \cdot 184)$ and a slight reduction in $\mathrm{p} 27^{\mathrm{Kip} 1}$ and $\mathrm{p} 53 \mathrm{mRNA}$ expression, whereas $27^{\mathrm{kip} 1}$ protein nuclear expression was slightly increased in G3 and G4 in the genistein arm compared with placebo.

The mRNA and protein expression results for the cell cycle-related biomarkers were coherent in both study arms, showing increased levels of $\mathrm{p} 21^{\text {Waf1/Cip } 1}$ and $\mathrm{p} 53$ and reduced levels of $\mathrm{p} 27^{\mathrm{Kip} 1}$ in tumour tissue compared to normal tissue. The percentage $\mathrm{p} 21^{\text {Waf1/Cip } 1}$ positive cells was less than $1 \%$ in normal prostate tissue and increased with increasing Gleason grade to about $2 \%$ in $\mathrm{G} 3$ cells and $4 \%$ in G4 cells. Fig. 4(a) depicts a patient from the genistein group showing an increasing number of $\mathrm{p} 21^{\text {Waf1/Cip } 1}$ positive nuclei from normal tissue to G4. The nuclear expression of $\mathrm{p} 27^{\mathrm{Kip} 1}$ was significantly reduced in G3 ( $P=0 \cdot 016)$ compared to normal, whereas the
mRNA level was non-significantly reduced in tumour compared to normal cells (Fig. 3(b) and (e)). Fig. 4(b) shows a patient from the placebo group with strong nuclear/weak cytoplasmic staining intensity in normal cells and weak nuclear/strong cytoplasmic $\mathrm{p} 27^{\mathrm{Kip} 1}$ staining in G3. Fig. 4(c) shows a patient treated with placebo with no p53 positive cells in normal tissue and with single p53 positive cells in G3 and G4 tissues.

\section{Proliferation- and apoptosis-related biomarkers}

Genistein intervention had no significant effects on the protein expression of Ki67, BAX or BCL-2 (Fig. 5).

In both study arms, Ki67 and BAX expression increased with increasing Gleason grade. Ki67 was expressed by $1 \%$ of normal epithelial cells and it increased significantly to $3 \%$ 
(a)

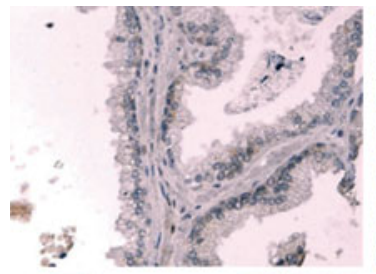

(b)

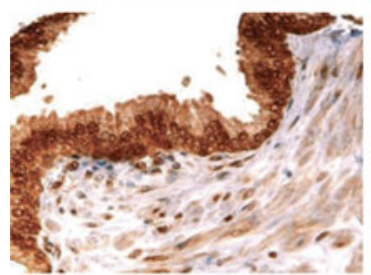

(c)

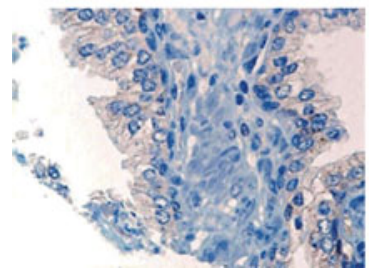

Normal
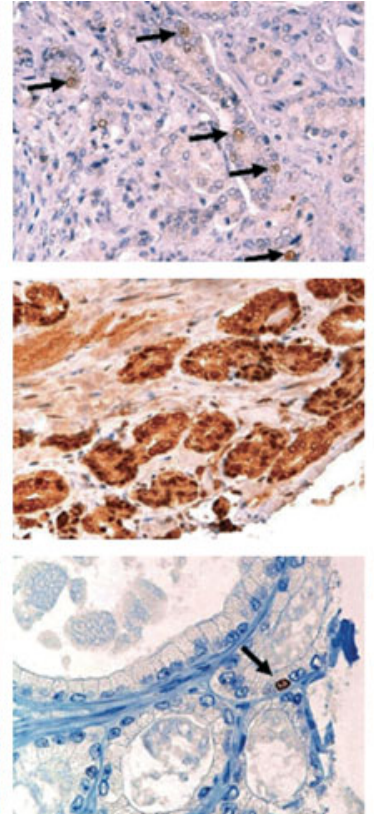

G3
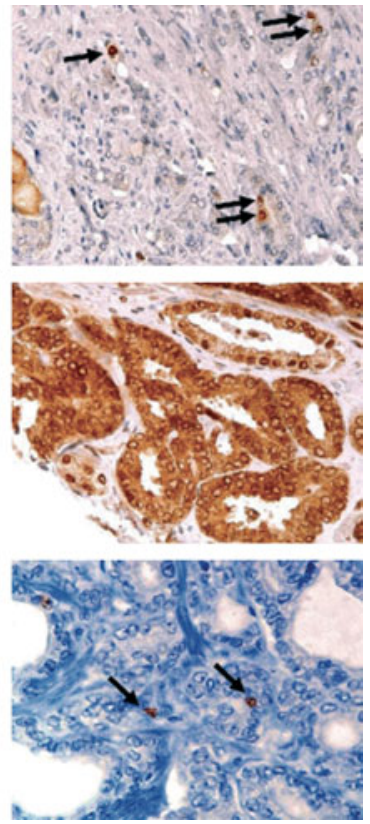

G4

Fig. 4. Immunohistochemical staining of cell cycle-related biomarkers. Each row shows tissue microarray spots from a single patient containing normal, Gleason grade 3 (G3) and/or Gleason grade 4 (G4) prostate tissues. Magnification $\times 400$ for (a) cyclin-dependent kinase inhibitor $1 \mathrm{~A}$ and (b) cyclin-dependent kinase inhibitor 1B. Magnification $\times 600$ for $(c)$ tumour protein $p 53$.

in $\mathrm{G} 3$ cells $(P<0 \cdot 001)$ and further to approximately $5 \%$ in G4 cells (Fig. 5(a)). Fig. 6(a) depicts a patient treated with genistein showing increasing number of Ki67 positive cells from normal tissue to G4. BAX protein expression increased significantly $(P=0 \cdot 011)$ in G3 compared to normal cells
(Fig. 5(b)). Fig. 6(b) shows a patient treated with genistein with weak cytoplasmic BAX staining in normal tissue and increasing intensity in tumour tissue. BCL-2 was in general not expressed in normal epithelial cytoplasm (Fig. 5(c)). The increased expression in malignant tissue was not statistically
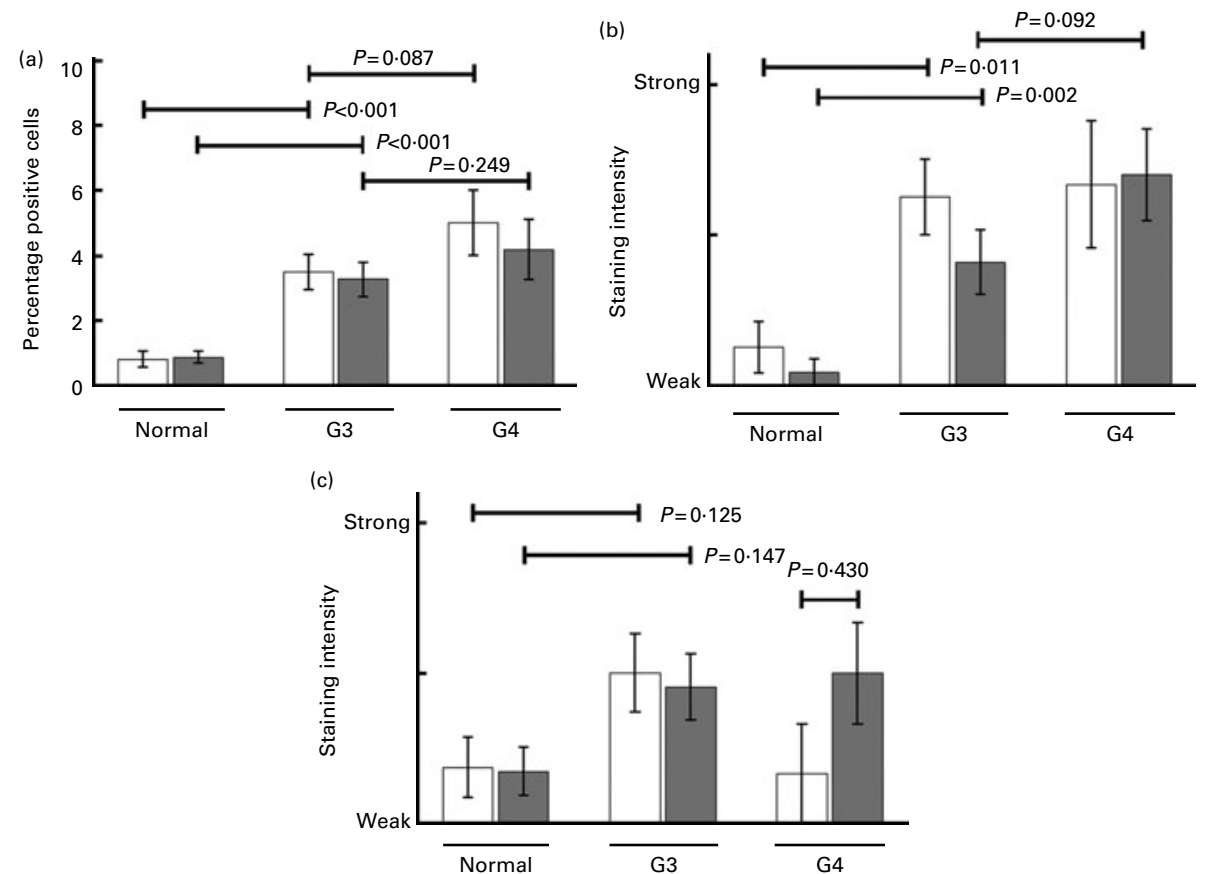

Fig. 5. Expression of proliferation- and apoptosis-related biomarkers. The protein expression of (a) Ki67, (b) B-cell CLL/lymphoma 2-associated X protein and (c) B-cell CLL/lymphoma 2 was determined by immunohistochemical staining of tissue microarrays containing normal and Gleason grade 3 (G3) and/or Gleason grade 4 (G4) spots of prostatectomy specimens. The figures show the mean staining intensity or percentage positive cells, with their standard errors. $\square$, Placebo; $\square$, genistein. 
(a)

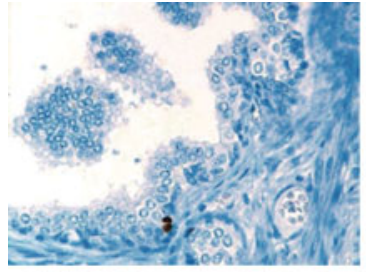

(b)

(c)
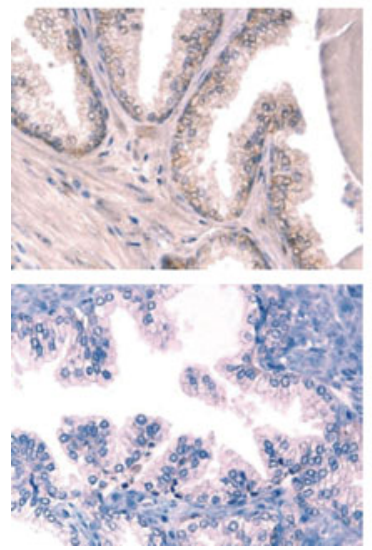

Normal
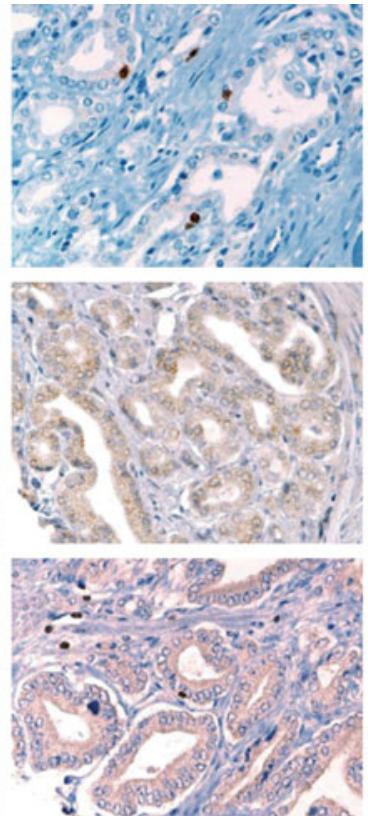

G3
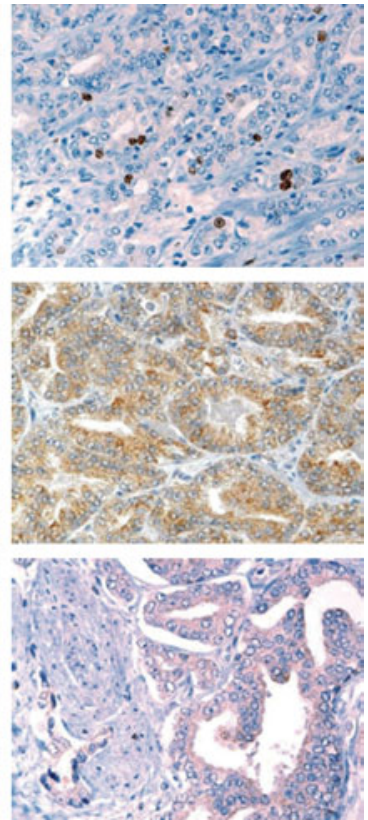

G4

Fig. 6. Immunohistochemical staining of proliferation- and apoptosis-related biomarkers. Each row shows tissue microarray spots from a single patient containing normal, Gleason grade 3 (G3) and Gleason grade 4 (G4) prostate tissues. Magnification $\times 400$. (a) Ki67, (b) B-cell CLL/lymphoma 2-associated X protein and (c) B-cell CLL/lymphoma.

significant $(P=0 \cdot 125)$. Fig. 6(b) shows a patient treated with genistein with weak BCL-2 staining in normal tissue and stronger staining in tumour tissue.

\section{Neuroendocrine differentiation-related biomarkers}

Genistein intervention had no significant effect on NSE or CgA (Fig. 7).

In both study arms, the expression of the neuroendocrine differentiation-related biomarkers indicated reduced levels with increasing Gleason grade. Fig. 8(a) shows a patient treated with placebo with decreasing number of NSE-positive cells in G3 tumour. There was a clear presence of CgA-positive cells in normal tissue, which was completely abolished in G4 tissue in both treatment arms $(P<0.001$; Fig. 7(b)). Fig. 8(b) shows a patient treated with genistein with decreasing number of CgA-positive cells with higher Gleason grade.

\section{Discussion}

To our knowledge, this is the first study which exclusively investigates the effects by genistein alone in men with PCa. We showed that genistein intervention significantly downregulated the mRNA expression levels of KLK4 in cancer cells in men with localised PCa. Genistein has previously been shown to decrease AR nuclear binding to the transcriptional binding site for $\mathrm{AR}^{(10)}$. We also report a decrease by genistein on most of the selected androgen-related biomarkers, corroborating the results of our in vitro studies ${ }^{(11)}$. However, the average plasma level in the present study was at least 25 -fold lower than the concentrations used in cell culture studies, indicating that in vivo nutritional relevant levels of genistein may have comparable effects to high-dose cell studies. This may be related to longer in vivo exposure. The androgen-related biomarkers used in this study have been attributed roles in the development or progression of PCa. $N K X 3 \cdot 1$ is an androgen-regulated homeobox gene located
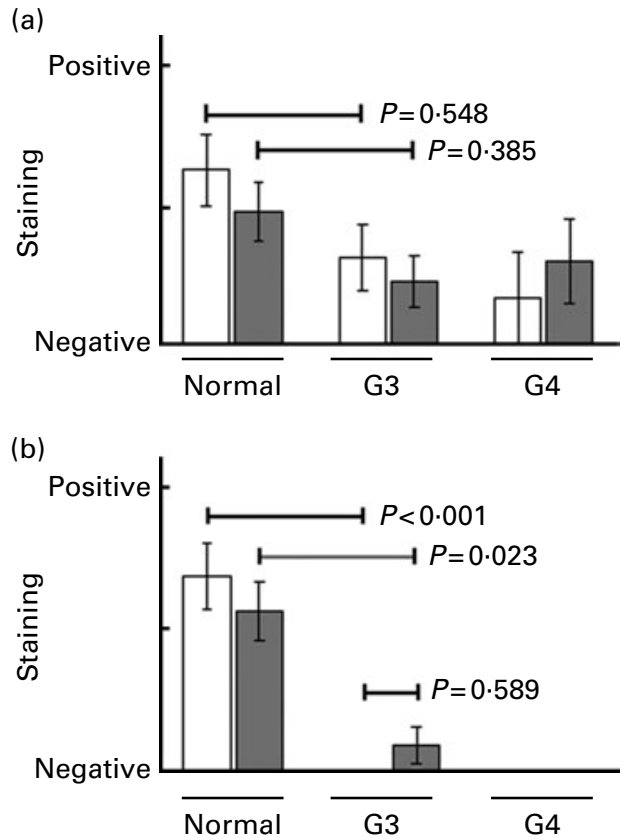

Fig. 7. Expression of neuroendocrine differentiation-related biomarkers. The protein expression of (a) neuron-specific enolase and (b) cytoplasmic chromogranin A was determined by immunohistochemical staining of tissue microarrays containing normal and Gleason grade 3 (G3) and/or Gleason grade 4 (G4) spots of prostatectomy specimens. The figures show the mean positive/ negative stain, with their standard errors. $\square$, Placebo; $\square$, genistein. 
(a)

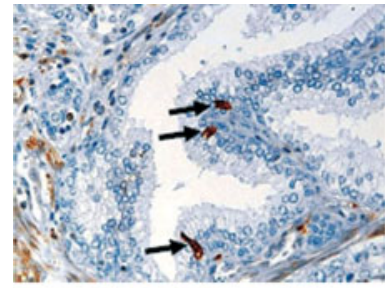

(b)

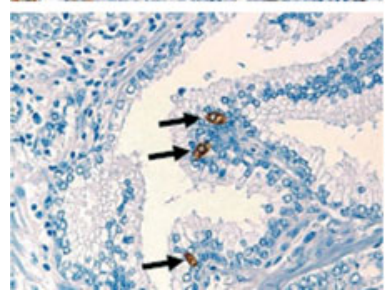

Normal
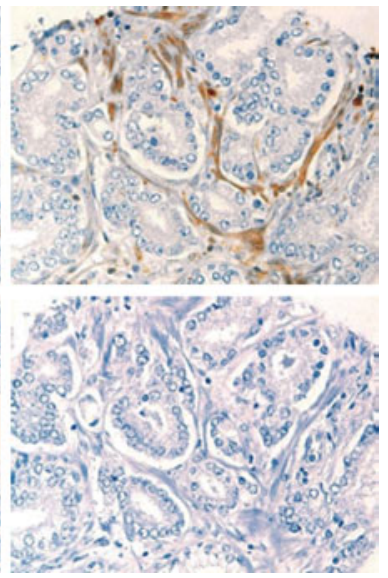

G3

Fig. 8. Immunohistochemical staining of neuroendocrine differentiationrelated biomarkers. Both rows show tissue microarray spots from the same patient containing normal and Gleason grade 3 (G3) prostate tissues. Magnification $\times 400$. (a) neuron-specific enolase and (b) cytoplasmic chromogranin A.

on chromosome $8 \mathrm{p} 21 \cdot 2$, a region that shows a high degree of loss of heterozygosity in $\mathrm{PCa}^{(12,13)}$. Reports of its function and expression in PCa have been conflicting. However, most reports indicate that $\mathrm{NKX} 3 \cdot 1$ acts as a non-classical tumour suppressor and that its expression is reduced in primary $\mathrm{PCa}$ and further reduced in metastatic $\mathrm{PCa}^{(14,15)}$. However, our immunohistochemistry results indicated a translocation of NKX3.1 from the nucleus to the cytoplasm and not a total reduction with increasing Gleason grade. Interestingly, increased cytoplasmic stain intensity in primary PCa was briefly mentioned by Gurel et $a l^{(15)}$, although it was not taken into account during scoring. Different splicing variants of NKX3.1 and antibodies have previously been attributed for the conflicting results of NKX3.1 expression. Human kallikrein 4 (KLK4), a serine protease belonging to the prostate specific antigen-related kallikrein family, is overexpressed in $\mathrm{PCa}$ and might be a proliferative factor acting directly or indirectly on cell cycle regulators ${ }^{(16)}$. Increased KLK4 levels in PC-3 cells have also been associated with a transcriptional repression of E-cadherin and increased Matrigel motility ${ }^{(17)}$. Our results were consistent with previous reports showing an overexpression of KLK 4 mRNA and protein in PCa.

There are no previous reports on in vivo studies on the effects of genistein on the cell cycle-related genes $p 21^{\text {Waf1/Cip } 1}, p 27^{\text {Kip } 1}$ and $p 53$. However, in vitro studies on prostate, breast and lung cancer cells report that genistein up-regulates them, in line with its inhibitory effect on cell cycle progression ${ }^{(18,19)}$. We did not observe any significant effects by genistein, but the mRNA levels of $\mathrm{p} 21^{\text {Waf1/Cip } 1}, \mathrm{p} 27^{\mathrm{Kip} 1}$ and $\mathrm{p} 53$ were slightly down-regulated. The reason for this discrepancy is not clear. Interestingly, we showed an increased expression of $\mathrm{p} 21^{\text {Waf1/Cip } 1}$ and $\mathrm{p} 53$ mRNA and protein expression in G3 and that the expression may further increase with increasing Gleason grade. Navone et al. ${ }^{(20)}$ showed that p53 accumulation is associated with late-stage PCa. With a cutoff

value at $5 \%$ of $\mathrm{p} 53$ positive cells, they detected no accumulation in nineteen patients with Gleason score 5-7, whereas nineteen of forty-two patients with Gleason score 8-10 showed accumulation. p21 Waf1/Cip1 may act both as a cell cycle negative regulator and anti-apoptotic mediator and its protein expression has been shown to correlate strongly with $\mathrm{p} 53$ in $\mathrm{PCa}^{(21,22)}$. The reduction of $\mathrm{p} 27^{\mathrm{Kip} 1}$ mRNA and nuclear protein expression in both study arms and the small reversal of protein expression in G3 and G4 by genistein intervention may have an interesting implication for the cell cycle modulating properties of genistein. Loss of phosphatase and tensin homologue function and/or constitutive activation of Akt/protein kinase $\mathrm{B}$ by the phosphoinositide kinase-3 pathway, commonly found in $\mathrm{PCa}$, will reduce the expression of $\mathrm{p} 27^{\mathrm{Kip} 1(23,24)}$. In vitro studies on genistein indicate that it inhibits protein kinase $\mathrm{B}$ constitutive activation by re-establishing phosphatase and tensin homologue expression ${ }^{(25,26)}$. Although the increase of $\mathrm{p} 27^{\mathrm{kip} 1}$ in $\mathrm{G} 3$ and G4 by genistein was not significant, this result may indicate the mechanism for its $G_{1}$ cell cycle arrest and proliferation inhibition of tumour cells ${ }^{(27)}$. Further research is needed in this connection.

The proliferation biomarker Ki67 was clearly up-regulated in tumour tissue, although it was not modulated by genistein Our detection of $1 \% \mathrm{Ki} 67$ positive luminal cells in normal and $4-6 \%$ in tumour tissue corroborates with previous publications $^{(28)}$. The increasing levels of Ki67, p21 Waf1/Cip1 and $\mathrm{p} 53$ may indicate that loss of p53 function already is present in some G3 cancers.

The apoptotic biomarkers BAX and BCL-2 were both significantly or near-significantly up-regulated in PCa, corroborating a previous report on Gleason score $5-10^{(29)}$. We observed no significant regulation of BAX or BCL-2 by genistein intervention.

The role of neuroendocrine markers as prognostic factors is controversial, although the serum level of CgA and NSE seems to have a prognostic value in castration-resistant $\mathrm{PCa}^{(30-32)}$. Genistein treatment of LNCaP human prostatic adenocarcinoma cells has been shown to induce several positive biomarkers for neuroendocrine differentiation including $\mathrm{CgA}^{(19)}$. We detected very few CgA- and NSE-positive cells in tumour tissue. The reduction of CgA-positive cells in tumour tissue corroborates earlier results from serum, showing a reduction in localised PCa and an increase in castration-resistant $\mathrm{PCa}^{(31)}$

The ability of genistein to modulate the progression of existing PCa is not clear. In the present study, we have investigated the effects of pure genistein. As opposed to the majority of chemopreventive reports of genistein treatment, some recent studies on mouse xenograft models indicate genistein to promote increased metastasis of PCa, whereas isoflavones containing genistein and daidzein do not ${ }^{(33-37)}$. Other studies show that dietary genistein inhibits metastases of human cancer, including PCa, in mice and that the discrepancy may be related to methodology ${ }^{(38,39)}$. In addition, Setchell et al. ${ }^{(40)}$ raised doubts about the use of rodent models for gaining insight into the effect of isoflavones in humans due to differences in the metabolism of genistein. We did not detect any signs of cancer-promoting effects in our study with pure 
genistein intervention in our human study subjects having early localised PCa.

Overall, genistein intervention at nutritionally relevant levels in patients with early PCa modulated several biomarkers which may be related to cancer prediction and progression. Genistein may have an inhibitory effect on androgen-related biomarkers. We also suggest a possible mechanism as to how genistein may induce cell cycle arrest and inhibition of proliferation in PCa. A limitation in our study is the small number of cases included and also the relative short time of intervention. Further studies on the effects of genistein in $\mathrm{PCa}$ are warranted, including clinical studies examining biomarkers and in vitro studies investigating its mechanisms of action.

\section{Acknowledgements}

The authors are grateful for the technical assistance by Olov Ogren and the assistance by DSM Nutritional Products Limited in the process of obtaining approvals and for supplying the study capsules. O. K. is a Georgia Cancer Coalition Distinguished Cancer Scholar. This was an investigator-initiated and -driven study. The work was performed at Oslo University Hospital, Aker and the study was solely financed with official grants from the hospital. B. L. and S. J. K. designed the study and had overall responsibility for the project. O. K., F. S., K. A. T. and A. S. assisted in the design of various parts of the study. B. L. was responsible for the subject selection, data collection and final data analysis. B. L. and H. R. conducted the PCR analysis. C. H. and A. S. performed the laser capture microdissection and conducted the immunohistochemical analysis. J. Y. conducted the androgen-related gene immunohistochemistry. L. M. D. conducted the statistical analysis. B. L., S. J. K., K. A. T. and A. S. drafted the paper, and all authors contributed to the final completion of the manuscript. The authors have no conflicts of interest.

\section{References}

1. Madu CO \& Lu Y (2010) Novel diagnostic biomarkers for prostate cancer. J Cancer 1, 150-177.

2. Lopergolo A \& Zaffaroni N (2009) Biomolecular markers of outcome prediction in prostate cancer. Cancer $\mathbf{1 1 5}$, 3058-3067.

3. Netto GJ \& Epstein JI (2010) Theranostic and prognostic biomarkers: genomic applications in urological malignancies. Pathology 42, 384-394.

4. Banerjee S, Li Y, Wang Z, et al. (2008) Multi-targeted therapy of cancer by genistein. Cancer Lett 269, 226-242.

5. Steiner C, Arnould S, Scalbert A, et al. (2008) Isoflavones and the prevention of breast and prostate cancer: new perspectives opened by nutrigenomics. Br J Nutr 99E, Suppl. 1, ES78-E108.

6. Lazarevic B, Boezelijn G, Diep LM, et al. (2011) Efficacy and safety of short-term genistein intervention in patients with localized prostate cancer prior to radical prostatectomy: a randomized, placebo-controlled, double-blind phase 2 clinical trial. Nutr Cancer 63, 889-898.

7. Ullmann U, Metzner J, Frank T, et al. (2005) Safety, tolerability, and pharmacokinetics of single ascending doses of synthetic genistein (Bonistein) in healthy volunteers. Adv Ther 22, 65-78.

8. Bonner RF, Emmert-Buck M, Cole K, et al. (1997) Laser capture microdissection: molecular analysis of tissue. Science 278, 1481-1483.

9. Rubin MA, Dunn R, Strawderman M, et al. (2002) Tissue microarray sampling strategy for prostate cancer biomarker analysis. Am J Surg Pathol 26, 312-319.

10. Davis JN, Kucuk O \& Sarkar FH (2002) Expression of prostate-specific antigen is transcriptionally regulated by genistein in prostate cancer cells. Mol Carcinog 34, 91-101.

11. Lazarevic B, Karlsen SJ \& Saatcioglu F (2008) Genistein differentially modulates androgen-responsive gene expression and activates JNK in LNCaP cells. Oncol Rep 19, 1231-1235.

12. Bova GS, Carter BS, Bussemakers MJ, et al. (1993) Homozygous deletion and frequent allelic loss of chromosome $8 \mathrm{p} 22$ loci in human prostate cancer. Cancer Res 53, 3869-3873.

13. Bieberich CJ, Fujita K, He WW, et al. (1996) Prostate-specific and androgen-dependent expression of a novel homeobox gene. J Biol Chem 271, 31779-31782.

14. Abate-Shen C, Shen MM \& Gelmann E (2008) Integrating differentiation and cancer: the Nkx3.1 homeobox gene in prostate organogenesis and carcinogenesis. Differentiation 76, 717-727.

15. Gurel B, Ali TZ, Montgomery EA, et al. (2010) NKX3.1 as a marker of prostatic origin in metastatic tumors. Am J Surg Pathol 34, 1097-1105.

16. Klokk TI, Kilander A, Xi Z, et al. (2007) Kallikrein 4 is a proliferative factor that is overexpressed in prostate cancer. Cancer Res 67, 5221-5230.

17. Veveris-Lowe TL, Lawrence MG, Collard RL, et al. (2005) Kallikrein 4 (hK4) and prostate-specific antigen (PSA) are associated with the loss of E-cadherin and an epithelialmesenchymal transition (EMT)-like effect in prostate cancer cells. Endocr Relat Cancer 12, 631-643.

18. Kobayashi T, Nakata $T$ \& Kuzumaki $T$ (2002) Effect of flavonoids on cell cycle progression in prostate cancer cells. Cancer Lett 176, 17-23.

19. Pinski J, Wang Q, Quek ML, et al. (2006) Genistein-induced neuroendocrine differentiation of prostate cancer cells. Prostate 66, 1136-1143.

20. Navone NM, Troncoso P, Pisters LL, et al. (1993) p53 protein accumulation and gene mutation in the progression of human prostate carcinoma. J Natl Cancer Inst 85 , 1657-1669.

21. Janicke RU, Sohn D, Essmann F, et al. (2007) The multiple battles fought by anti-apoptotic p21. Cell Cycle 6, 407-413.

22. Shiraishi T, Watanabe M, Muneyuki T, et al. (1998) A clinicopathological study of p53, p21 (WAF1/CIP1) and cyclin D1 expression in human prostate cancers. Urol Int 61, 90-94.

23. Li J, Yen C, Liaw D, et al. (1997) PTEN, a putative protein tyrosine phosphatase gene mutated in human brain, breast, and prostate cancer. Science 275, 1943-1947.

24. Medema RH, Kops GJ, Bos JL, et al. (2000) AFX-like Forkhead transcription factors mediate cell-cycle regulation by Ras and PKB through p27kip1. Nature 404, 782-787.

25. Li Y \& Sarkar FH (2002) Inhibition of nuclear factor kappaB activation in PC3 cells by genistein is mediated via Akt signaling pathway. Clin Cancer Res 8, 2369-2377.

26. Kikuno N, Shiina H, Urakami S, et al. (2008) Genistein mediated histone acetylation and demethylation activates tumor suppressor genes in prostate cancer cells. Int $J$ Cancer 123, 552-560

27. Shen JC, Klein RD, Wei Q, et al. (2000) Low-dose genistein induces cyclin-dependent kinase inhibitors 
and $G(1)$ cell-cycle arrest in human prostate cancer cells. Mol Carcinog 29, 92-102.

28. Barbisan F, Mazzucchelli R, Santinelli A, et al. (2010) Expression of prostate stem cell antigen in high-grade prostatic intraepithelial neoplasia and prostate cancer. Histopathology 57, 572-579.

29. Krajewska M, Krajewski S, Epstein JI, et al. (1996) Immunohistochemical analysis of bcl-2, bax, bcl-X, and mcl-1 expression in prostate cancers. Am J Pathol 148, 1567-1576.

30. Taplin ME, George DJ, Halabi S, et al. (2005) Prognostic significance of plasma chromogranin a levels in patients with hormone-refractory prostate cancer treated in Cancer and Leukemia Group B 9480 study. Urology 66, 386-391.

31. Kamiya N, Akakura K, Suzuki H, et al. (2003) Pretreatment serum level of neuron specific enolase (NSE) as a prognostic factor in metastatic prostate cancer patients treated with endocrine therapy. Eur Urol 44, 309-314, discussion 314.

32. Hvamstad T, Jordal A, Hekmat N, et al. (2003) Neuroendocrine serum tumour markers in hormone-resistant prostate cancer. Eur Urol 44, 215-221.

33. Hillman GG, Wang Y, Kucuk O, et al. (2004) Genistein potentiates inhibition of tumor growth by radiation in a prostate cancer orthotopic model. Mol Cancer Ther 3, $1271-1279$
34. Raffoul JJ, Banerjee S, Che M, et al. (2007) Soy isoflavones enhance radiotherapy in a metastatic prostate cancer model. Int J Cancer 120, 2491-2498.

35. Singh-Gupta V, Zhang H, Yunker CK, et al. (2010) Daidzein effect on hormone refractory prostate cancer in vitro and in vivo compared to genistein and soy extract: potentiation of radiotherapy. Pharm Res 27, 1115-1127.

36. Nakamura H, Wang Y, Kurita T, et al. (2011) Genistein increases epidermal growth factor receptor signaling and promotes tumor progression in advanced human prostate cancer. PLoS One 6, e20034.

37. El Touny LH \& Banerjee PP (2009) Identification of a biphasic role for genistein in the regulation of prostate cancer growth and metastasis. Cancer Res 69, 3695-3703.

38. Lakshman M, Xu L, Ananthanarayanan V, et al. (2008) Dietary genistein inhibits metastasis of human prostate cancer in mice. Cancer Res 68, 2024-2032.

39. Gu Y, Zhu CF, Dai YL, et al. (2009) Inhibitory effects of genistein on metastasis of human hepatocellular carcinoma. World J Gastroenterol 15, 4952-4957.

40. Setchell KD, Brown NM, Zhao X, et al. (2011) Soy isoflavone phase II metabolism differs between rodents and humans: implications for the effect on breast cancer risk. Am J Clin Nutr 94, 1284-1294. 